\title{
Neurobehavioral Deficit Due to Ischemic Brain Damage Limited to Half of the CA1 Sector of the Hippocampus
}

\author{
Roland N. Auer, ${ }^{1}$ Murray L. Jensen, ${ }^{1}$ and lan Q. Whishaw ${ }^{2}$ \\ 'Neuroscience Research Group, University of Calgary, Alberta, Canada T2N 4N1, and 2Department of Psychology, \\ University of Lethbridge, Alberta, Canada T1K 3M4
}

It is well known that ischemia causes neuronal necrosis in selectively vulnerable sectors of the hippocampus. Since the hippocampus is involved in spatial navigation, learning, and memory, selective deficits in these areas may arise from ischemic brain damage. The objective of this study was to test whether a minimal ischemic insult, producing selective neuronal necrosis restricted to only a portion of the CA1 pyramidal cells of the hippocampus, could produce a detectable spatial navigation deficit.

Male Wistar rats received 9 min of forebrain ischemia induced by carotid clamping and hypotension or sham operation with exposure of the carotid arteries. The rats were allowed to recover and were tested on a simple place task, a place learning-set task, and a pattern discrimination task in swimming pools paradigms. Subsequently, the rats were perfusion-fixed and their entire brains subjected to quantitative histopathologic analysis. Although both ischemic and sham-operated groups learned the simple place task, the learning-set task revealed defects in spatial navigation, reflected as increased errors and latency in the performance of the ischemic rats. In the subsequent pattern discrimination task, the ischemic group was superior to the control group, which perseverated by attempting to use a place strategy to solve the discrimination. Quantitative neuropathology revealed neuronal necrosis in the ischemia group limited to $50 \%$ of the CA1 zone of the hippocampus. Extrahippocampal damage consisted of rare cortical neuronal necrosis in 2 of 6 animals.

The results demonstrate that the learning-set water task is sensitive and specific for hippocampal damage. Second, place learning deficits are produced in rats even with subtotal lesions limited to half of the vulnerable sector of the hippocampus. These findings may be relevant to human memory deficits seen with mild ischemic brain damage in clinical situations.

Cerebral ischemia is seen in 2 common clinical situationscardiac arrest and atherosclerosis of the carotid or vertebrobasilar artcrics. Pcoplc surviving cpisodes of ccrcbral ischemia

Received June 27, 1988; revised Sept. 19, 1988; accepted Sept. 20, 1988.

This investigation was supported by the Alberta Mental Health Research Council, the Medical Research Council of Canada (Grant MA-9935 to R.N.A.), and the Natural Sciences and Engineering Research Council of Canada (Grant OPGIN 012 to I.Q.W.). We wish to thank Ms. E. Tingle for typing the manuscript.

Correspondence should be addressed to Dr. R. N. Auer, Neuroscience Research Group, The University of Calgary, 3330 Hospital Drive NW, Calgary, Alberta, Canada T2N $4 \mathrm{~N} 1$.

Copyright $(1989$ Society for Neuroscience $0270-6474 / 89 / 051641-07 \$ 02.00 / 0$ often show a persistent memory deficit (Volpe and Hirst, 1983; Cummings et al., 1984; Zola-Morgan et al., 1986), and neuropathologic examination of the brain often reveals selective affectation of a portion of the hippocampus variously known to neuropathologists as the vulnerable sector, Sommer's sector (Sommer, 1880), or the H1 field of Rose (1926). Researchers commonly term this susceptible region the hippocampal CAl zone according to the terminology of Lorente de Nó (1934).

In ischemia, experimental evidence obtained in animals has causally linked selective necrosis of CA1 pyramidal cells to an ischemia-induced release of the excitatory amino acid glutamate (Benveniste et al., 1984; Drejer et al., 1985; Rothman and Olney, 1986). This ischemia-induced release of glutamate likely occurs in man as well (Engelsen et al., 1985), and possibly underlies selective damage to the human hippocampus. Glutamate may cause ischemic neuronal death by acting at excitatory $N$-methylD-Aspartate (NMDA) receptors (Simon et al., 1984), which play an important physiological role in long-term potentiation and memory (Collingridge et al., 1983; Wigström et al., 1986). Thus, the high concentration of NMDA excitatory receptors on the dendritic trees of hippocampal CAl pyramidal cells (Greenamyre et al., 1985; Monaghan et al., 1985) likely explains the long-known selective vulncrability of the CAl zone of the hippocampus to ischemic brain damage.

Although there is strong evidence that total destruction of hippocampal CA1 neurons is sufficient to cause a memory deficit (Zola-Morgan et al., 1986), it is still presently unclear in man and in animals to what degree subtotal ischemic hippocampal damage may occur without a memory deficit ensuing. The present investigation was designed to determine whether a low dose of ischemic insult to the brain, causing damage limited to a portion of CA1 of the hippocampus, could cause a detectable behavioral deficit. The results demonstrate that $50 \%$ selective neuronal necrosis of only the CAl hippocampal neuronal population in the brain can cause a deficit in spatial learning and memory in the rat.

\section{Materials and Methods}

Ischemia model. A modification of the ischemia model developed by Smith and coworkers (Smith et al., 1984a) was used. This 2-vessel carotid-occlusion model produces damage concentrated in the septal two-thirds of the rat hippocampus (Smith et al., 1984b) due to continued blood supply of the temporal third of the hippocampus (Smith et al., 1984a) by the open vertebrobasilar arterial system. Briefly, forebrain ischemia was induced by a combination of carotid clamping and hypotension. Twelve male Wistar rats were anesthetized in 3\% halothane, intubated, and ventilated on a Starling type ventilator, using a $2: 1 \mathrm{~N}_{2} \mathrm{O}$ / $\mathrm{O}_{2}$ mixture containing $0.7 \%$ halothane. A tail vein was cannulated, and a continuous infusion of suxamethonium chloride $(2 \mathrm{mg} / \mathrm{hr})$ was administered to maintain continuous paralysis. The tail artery was can- 
nulated, and blood pressure was continuously recorded via a Statham transducer (Gould P50, Oxnard, CA). A central venous catheter was inserted via the right jugular vein and attached to a prewarmed $10 \mathrm{cc}$ heparinized syringe.

After a period of physiologic stabilization of roughly $30 \mathrm{~min}, 6$ of the rats were given $5 \mathrm{mg} / \mathrm{kg}$ i.v. Trimethaphan (Arfonad, Hoffman-La Roche, Toronto, Canada). The rats were then exsanguinated into the prewarmed heparinized syringe. When the blood pressure reached $50 \mathrm{~mm} \mathrm{Hg}$, two Moria vessel clamps were placed around the carotid arteries. Blood pressure was maintained at $50 \mathrm{~mm} \mathrm{Hg}$ by withdrawal and reinfusion of the shed blood via the central venous catheter. Six sham-operated rats had their carotid arteries exposed but were not subject to carotid clamping.

After 9 min of ischemia, the carotid clamps were released, and the shed blood was reinfused. The animals were extubated, allowed to awaken, and submitted to neurobehavioral testing 8-10 weeks after surgery.

Neurobehavioral testing apparatus. The swimming pool task has been described in detail elsewhere (Whishaw, 1985a, b). Briefly, rats were trained and tested in a round white swimming pool measuring $146 \mathrm{~cm}$ (diameter) $\times 45 \mathrm{~cm}$ (height) and filled to a depth of $25 \mathrm{~cm}$ with water $\left(18^{\circ} \mathrm{C}\right)$ rendered opaque with the addition of $1000 \mathrm{gm}$ of powdered skim milk.

The room was dimly lit (room window curtains were drawn and room lights were dimmed). A double-layered translucent blue plastic curtain could be drawn around the pool to obscure room cues. Swimming latencies were recorded with a stopwatch, and swim patterns were drawn on a diagram of the swimming pool. In addition, the rats' swims were recorded from above with a video camera so that their behavior could be analyzed in greater detail during playback.

Four points on the pool rim were designated as north $(\mathrm{N})$, south $(\mathrm{S})$, east (E), and west (W). On this basis, the pool surface was divided into 4 quadrants of equal area, NE, NW, SE, and SW. When used, cues were located approximately at the center of designated quadrants.

Place task. The hidden platform $(13 \times 13 \mathrm{~cm})$ was always located in the center of the SW quadrant of the pool with its top surface $1.5 \mathrm{~cm}$ below the surface of the water (Whishaw et al., 1987). On a particular trial, a rat was released facing the wall of the pool from one of the starting locations according to a pseudorandom sequence that was different for each rat. On each day of training, each rat was exposed to each of the starting locations. On every trial that the platform was successfully located, the rat was allowed to remain on it for $10 \mathrm{sec}$ and if the platform was not located after $60 \mathrm{sec}$, the trial was terminated by removing the rat from the water. Testing continued for $10 \mathrm{~d}$, and after the last block of 4 trials, the platform was removed from the water. Each rat was then given one "probe" trial beginning at the $S$ start point and ending after $30 \mathrm{sec}$.

Learning set task. The learning-set task was similar to that described previously (Whishaw, 1985a, b). Briefly, 6 different platform locations were used and the platform was moved each day to one of these locations in sequence. Position 1 was in the center of the NE quadrant; position 2 , the pool center; position 3 , in the center of the SF quadrant; position 4 , the $\mathrm{N}$ start point $12 \mathrm{~cm}$ away from the pool wall; position 5 , the $\mathrm{W}$ start point about $12 \mathrm{~cm}$ away from the pool wall; and position 6 , in the center of the SW quadrant. Testing was conducted on consecutive days, with each rat receiving 16 trials on each day. If on a particular trial, a rat found the platform, it was permitted to remain there for $5 \mathrm{sec}$. Trials were given in pairs. The second trial of a pair was given immediately after a $5 \mathrm{sec}$ stay on the platform, and the same starting location was used. At the end of the second of each pair of trials, the rat was returned to a holding cage and approximately $5 \mathrm{~min}$ elapsed (during this interval, the remaining rats were tested) before the next pair of trials was given from a new starting location, and so on. The swim path was drawn on a map of the pool as the rat completed each trial. The latency to find the platform was recorded for every trial. If a rat swam directly to the platform, staying within an $18-\mathrm{cm}$-wide path from the start point to the platform, its performance was scored as correct; if it deviated from this route at any point, it received an error on that trial.

Pattern-discrimination task. For the pattern-discrimination task (Whishaw and Petrie, 1989), the cues were rubber balls $8 \mathrm{~cm}$ in diameter, with either horizontal or vertical black-and-white stripes painted on them. The positive cue-with horizontal stripes-was above a submerged Plexiglas platform that the rats could mount as a stair to climb and escape from the water. The negative cue-with vertical stripeswas above a 4-cm-diameter, round pedestal that the rats could not grasp or mount to escape from the water. The water level reached the bottom of the cues.
Eight trials were given each day, and each swim started from the east compass point. The cues were located in the center of adjacent quadrants and were alternated between the quadrants according to random sequence. Training lasted $10 \mathrm{~d}$. An error was scored if a rat went to the incorrect cue and attempted to mount it. Only one error was counted on any trial. Latency to reach and mount the platform associated with the positive cue was recorded on all tests.

Neuropathology. Rats were killed 13-15 weeks postischemia. They were re-anesthetized in $2-3 \%$ halothane and intubated. A thoracotomy was performed, and transcardiac perfusion was carried out using $4 \%$ formaldehyde, phosphate-buffered to $\mathrm{pH} 7.35$.

The brains were removed the following day and cut coronally at 2.8 $\mathrm{mm}$ intervals. The slices were processed in graded ethanols and xylol and embedded in paraffin. Subserial sectioning at $200 \mu \mathrm{m}$ intervals was performed in order to obtain sections from the cerebral cortex, caudate nucleus, hippocampus at standard levels (Fig. 1), diencephalon, brain stem, and cerebellum in all animals. The $8 \mu \mathrm{m}$ sections were then stained with $1 \%$ acid fuchsin and $0.1 \%$ cresyl violet as previously described (Auer et al., 1984b).

All telencephalic, brain-stem, and cerebellar sections in each brain were examined by light microscopy. Quantification of damaged hippocampal neurons was performed by direct visual counting of remaining viable neurons at 6 levels of the hippocampus along its septo temporal axis (Fig. 1). The number of viable neurons was then subtracted from the total number to obtain the percentage necrosis. Mean neuronal counts for the total number of hippocampal CA1 neurons normally present at each of the 7 levels were available from previous work (Auer et al., 1984a).

\section{Results}

\section{Ischemia model: neuropathology}

It was possible to extubate both ischemic and sham-operated groups roughly $30 \mathrm{~min}$ following the end of the operation. The postoperative course of both groups was uneventful. No postischemic seizures were seen in the ischemia group.

Double-stained sections of the subserially sectioned brain revealed damage virtually restricted to the hippocampus. The degree and distribution of damage along the septotemporal axis of the hippocampus is shown diagrammatically in Figure 1.

Unexpectedly, dead neurons could still be positively identified as acidophilic outlines even after the 13-15 week postischemic survival intervals (Fig. 2). In the pyramidal cell band, dendritic phagocytosis was seen and macrophages were present around necrotic CA1 perikarya. Interneurons outside the pyramidal cell band showed no changes in any animals, confirming previous reports of their resistance in ischemia (Johansen et al., 1983).

The hippocampal CA3 pyramidal cells and dentate granule cells were uniformly unaffected. A few necrotic CA4 neurons in the dentate hilus, probably representing somatostatin neurons (Johansen et al., 1987) were seen in 4 of 6 animals. These numbered 1-4 per section. In the parietal convexity of the cerebral cortex a few individual neuronophagic figures were seen, as several microglial cells surrounding an acidophilic cell remnant (Fig. 2). These numbered less than 10 necrotic cells per section and were present in 2 of the 6 rats in the ischemia group. All other extrahippocampal structures in the telencephalon, brain stem, and cerebellum were unaffected.

\section{Place task}

There were no differences in acquisition by the control and ischemia groups in learning the place task. Acquisition latency and error results are given in Figure 3. Analysis of variance gave significant trials effects on latency $[F(39,468)=10.5, p<0.001]$ and errors $[F(39,468)=9.0, p<0.001]$, but no significant treatment effects $[F(1,12)=3.7$ and $3.44, p<0.075$ and 0.088$]$ or interactions $[F(39,468)=0.92$ and $1.28, p=0.5$ and 0.12$]$ were seen. 


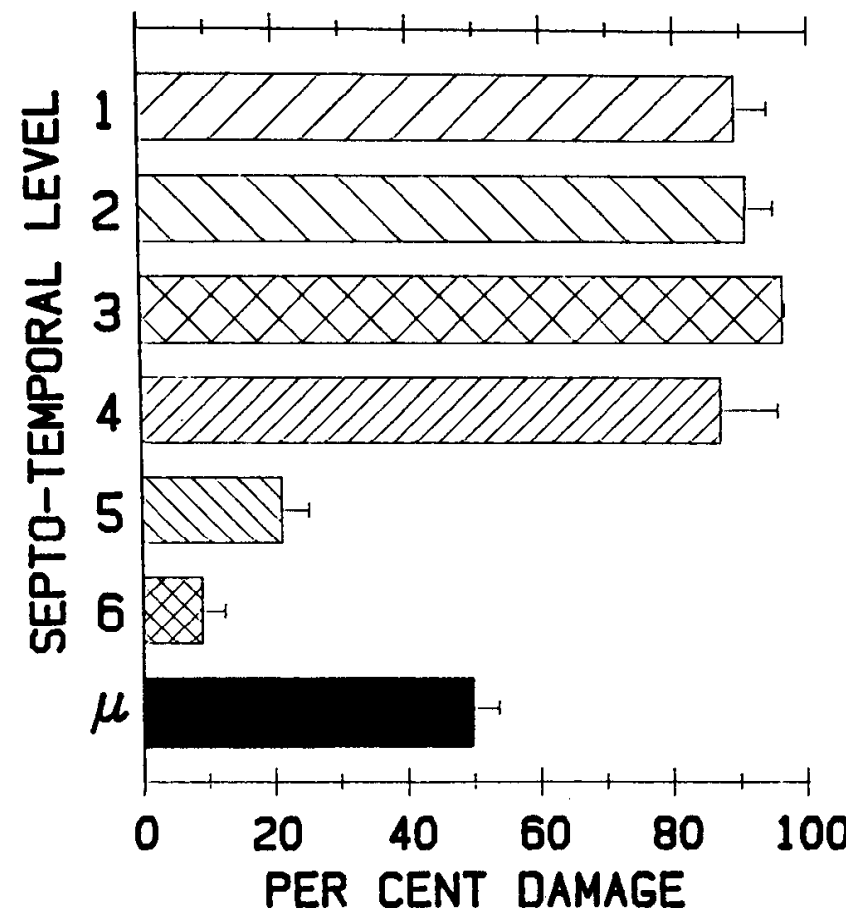

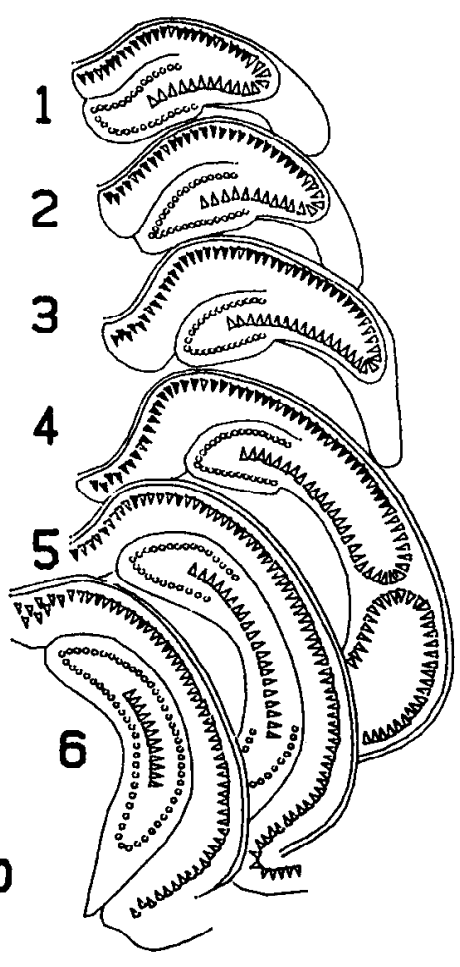

Figure 1. Density and distribution of ischemic damage from the septal end (level 1) to the temporal end (level 6 ) of the hippocampus. The percentage of CAI necrosis at each level and the mean for the entire hippocampus $(\mu)$ are shown as horizontal bars (mean $\pm \mathrm{SEM}$ ), with the corresponding septotemporal levels and damage depicted on the right.
When the platform was removed from the pool, for the probe trial given at the end of training, both groups spent more time swimming in the previously correct quadrant (mean percentage $\pm \mathrm{SEM}$; ischcmia $=50.5 \pm 4.4$, control $=50.8 \pm 5$ ). The analysis of distance swum gave no significant treatment difference $[F(1,12)=0.8, p=0.387]$, but there was a significant quadrant effect $[F(3,36)=39.67, p<0.00 \mathrm{I}]$ and no significant interaction $[F(3,36)=0.008, p=0.99]$. The number of times that the rats swam over the location in which the platform had been located or swam over comparable points in the other quadrants also did not give a significant treatment effect $[F(1,12)=$ $0.2, p=0.387$, but it did give a significant quadrant effect $[F(3,36)=32.9, p<0.001]$ and no significant interaction $[F(3,36)$ $=0.39, p=0.76]$. The ischemic rats crossed the previously correct quadrant's location an average of 3.5 times versus 3.8 times for the ischemic group. The mean crossing of the central areas of other quadrants was less than 0.5 for both groups.

\section{Learning-set task}

The ischemic group was significantly impaired in performance compared with the control group on the learning set task. On the latency measure, the main effects of groups $[F(1,12)=4.76$, $p=0.049]$, days $[F(5,60)=2.96, p=0.0188]$, and trials $[F(15,180)$ $=27.34, p<0.001]$ and the interaction of trials by days $[F(15,180)=1.72, p=0.05]$ were significant. The error measure gave only a significant main effects of group $[F(1,12)=9.21, p$ $=0.01]$ and trials $[F(15,180)=11.47, p<0.001]$. As inspection of Figure 4 shows, the control group had a longer first trial latency (they searched more persistently for the platform at its previous day's location), shorter second trial latencies (they acquired the new place response more quickly), and overall faster swim latencies across subsequent trials (they took more direct routes to the platform). Nevertheless, the overall performance of both groups was similar in that both showed most improvement between the first and second trials. This suggests that they both attempted to solve the learning set using the same strategy but that the ischemia group was less effective.

\section{Pattern-discrimination task}

The performance of the ischemia group on the pattern-discrimination task was superior to the performance of the control group (Fig. 5). In fact, after $10 \mathrm{~d}$ of training, the ischemia group had learned the task, whereas the control rats were performing at little better than chance. This conclusion was confirmed by analysis of variance that gave significant groups $[F(1,12)=25.4, p$ $=0.003]$, days $[F(9,108)=12.61, p<0.001]$, and group by days interaction $[F(9,108)=2.21, p=0.0265]$. Observation of behavior showed that the rats in the control group displayed a win-stay strategy; that is, they persisted in swimming to the location at which they had found the platform on the previous trial. The rats in the ischemia group, however, quickly learned to avoid the incorrect pattern and swim to the correct pattern.

\section{Discussion}

For years it has becn controversial whether a lesion of the hippocampal pyramidal cells alone was sufficient to cause memory impairment or whether damage to structures adjacent to the hippocampus was also necessary to cause a memory deficit. The temporal lobe white matter associated fibers (Horel, 1978) and the amygdaloid nuclei (Mishkin, 1978) have both been proposed to be necessarily damaged together with the hippocampus in order to produce a memory deficit.

The association of memory deficits with brain ischemia due to cardiac arrest or hypotension and the subsequent demonstration of hippocampal damage in the brain (Muramoto et al., 1979; Cummings et al., 1984; Zola-Morgan et al., 1986) suggest that memory deficits are indeed due specifically to hippocampal damage. Still, some extrahippocampal damage has always been present (Victor et al., 1961; Cummings et al., 1984; Zola-Morgan et al., 1986). However, in the best-studied case so far, extra- 


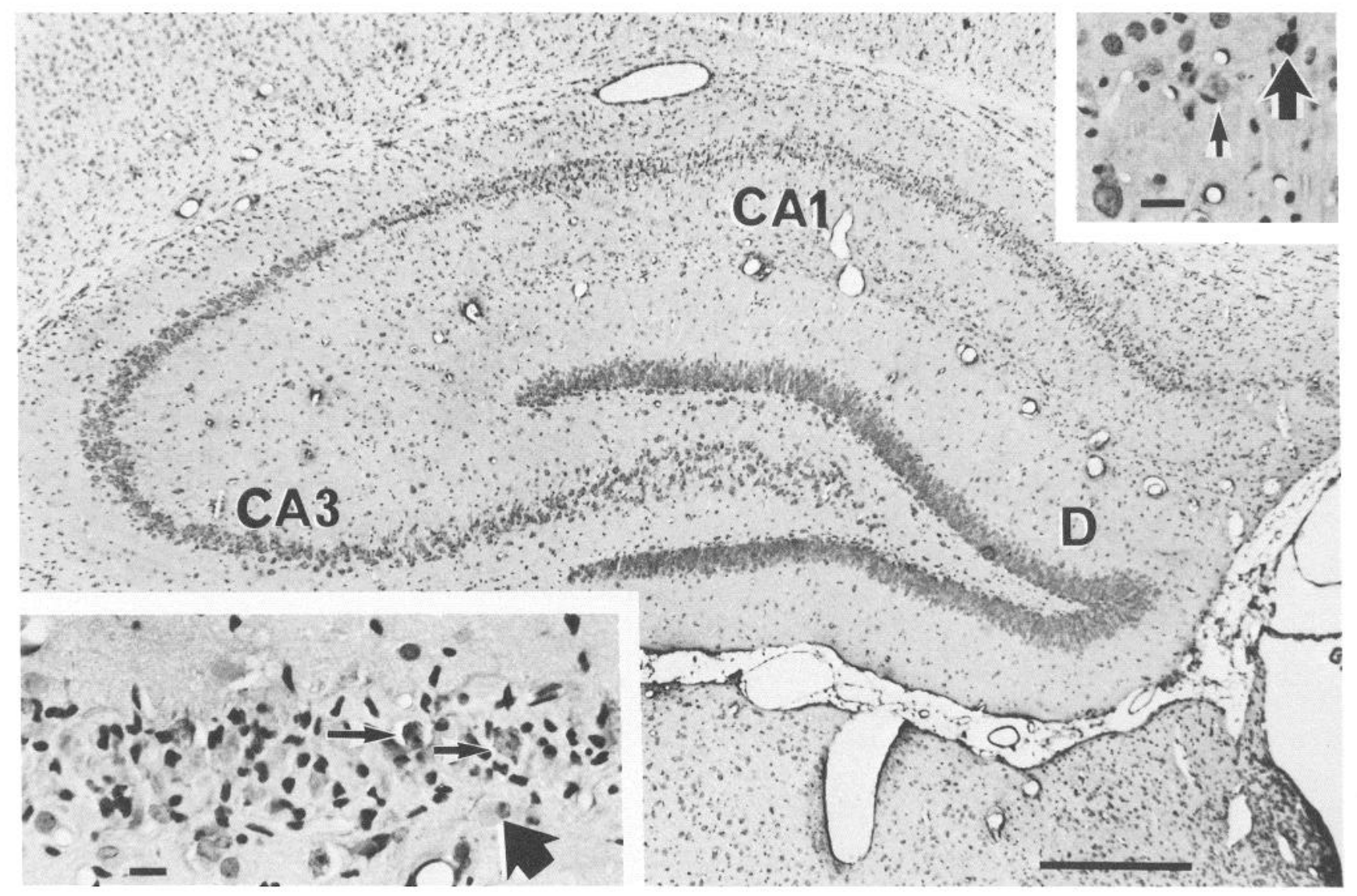

Figure 2. Histology 13-15 weeks after ischemia. The hippocampus at this septal level (corresponding to level 1, Fig. 1) shows damage in CA1, but CA3 and the dentate gyrus $(D)$ are preserved. Few CA1 neurons survive (small arrows, inset, lower left) and reactive astrocytes (large arrow) are present, along with numerous macrophages. The area of maximal cortical damage seen is shown in the inset (above right). The scant damage is evident as acidophilic outlines (small arrow), neuronophagic figures (large arrow), or dendritic phagocytosis (not shown). Only 2 out of 6 animals showed such scant neuronal necrosis in a few sections ( $<10$ cells/section). Ischemia $9 \mathrm{~min}, 14$ weeks survival. Acid fuchsin/cresyl violet. Scale bar, $400 \mu \mathrm{m}$; insets, $30 \mu \mathrm{m}$.

hippocampal damage was limited to disseminated patches of neuronal loss throughout the cerebral neocortex, to which the memory deficit could not reasonably be attributed (Zola-Morgan et al., 1986). Furthermore, the disseminated cortical lesions, if clinically significant, would have been expected to give rise to clinical signs and symptoms appropriate to the affected cortical region, in addition to producing a memory deficit. Mounting evidence from clinical material thus favors the view that selective memory deficits can be generated by brain lesions restricted to the hippocampus.

Behavioral studies in animals have demonstrated that hippocampal damage can produce learning-memory impairments (Mahut et al., 1982; Zola-Morgan and Squire, 1986), particularly on tasks that involve place learning (O'Keefe and Nadel, 1978). Place learning can be effectively examined in rats with spatial navigation tasks administered in a swimming pool, which requires navigation to an escape platform hidden just beneath the surface of water at a fixed location (Morris et al., 1982; Sutherland et al., 1983). Since there are no local cues present to guide swimming, the rat must locate the platform using the relational properties of many distal cues. On a simple place task, requiring that a rat learn only one platform location, severe impairments are typically obtained after complete hippocampal aspiration (Morris et al., 1982) or extensive granule cell or CA3 cell removal (Sutherland et al., 1983). In the present study, the im- pairment in the simple place task was not significant following incomplete CA1 lesions, but a significant impairment emerged on the more difficult learning-set task, which is typically not solved by hippocampal-damaged rats even after extensive training (Whishaw, 1987).

A number of features of the performance of the rats on the learning-set task are noteworthy. Control rats typically remember the previous day's platform location and search for it on the first trial of each test. Once finding it at its new location, however, they give up the previous day's response and swim immediately to the new location on the second and subsequent trials. Thus, all of their learning on each day's test occurs within one trial. The ischemic rats attempted to solve the task in the same way as the control rats. Their retention of each day's solution was impaired, and so they searched less on the first trial and had lower latencies than the control group. They were also less effective in learning new responses in one trial, so that their second trial latencies were greater than those of the control group. Finally, their performance across subsequent trials was less consistent than that of the control group.

A place learning deficit in the ischemic group was unexpectedly revealed in a second way by the pattern-discrimination task. This test is insensitive to hippocampal damage (Morris et al., 1986) and was administered as a behavioral control procedure to demonstrate the selective relation between CA1 dam- 

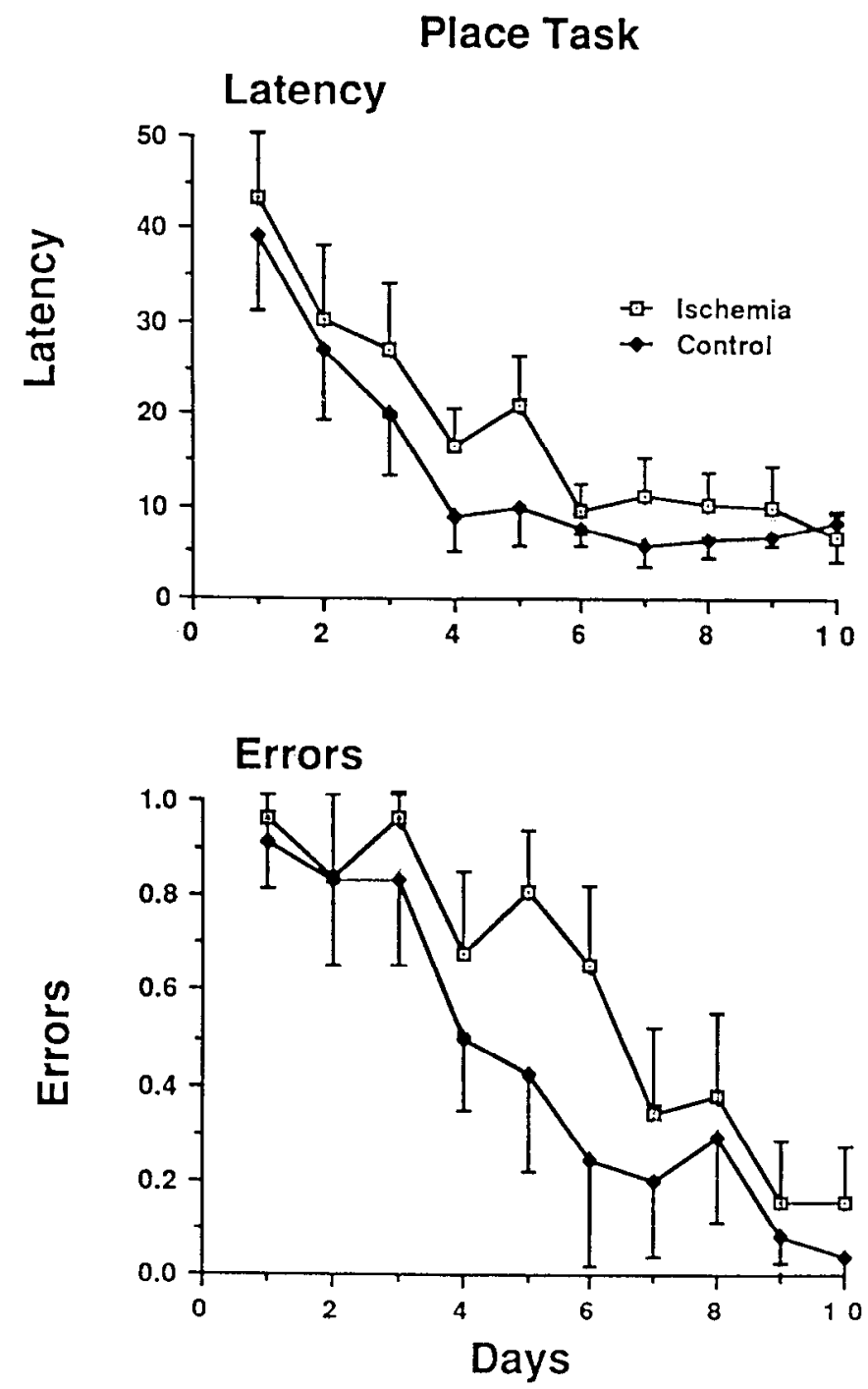

Figure 3. Mean latency and errors on a simple place task during which the hidden escape platform remained at the same location for $10 \mathrm{~d}$ of testing. Four trials were given each day, and curves represent the mean group performance. The differences were not significant for either latency $(p=0.075)$ or errors $(p=0.088)$.

age and place navigation impairments. Surprisingly, the ischemic group learned the task and the control group did not. Observation of the performance of the rats indicated that the control rats persisted in swimming to the location in which they had correctly found the platform previously. Presumably, their previous training on the place tasks had biased them to use a place strategy rather than the relevant pattern cues. The ischemic group, either because of a less well developed place response strategy or because they found a place strategy more difficult to use were able to adopt a new strategy and learn the pattern discrimination. This novel, counterintuitive result fortuitously confirms that the ischemic group was different from the control group.

These alterations in learning and memory were revealed to be due to damage essentially limited to the CA1 field of the hippocampus, with only a few necrotic neocortical neurons in some sections in 2 of 6 animals in the ischemia group. Although neocortical damage could have been underestimated as a result
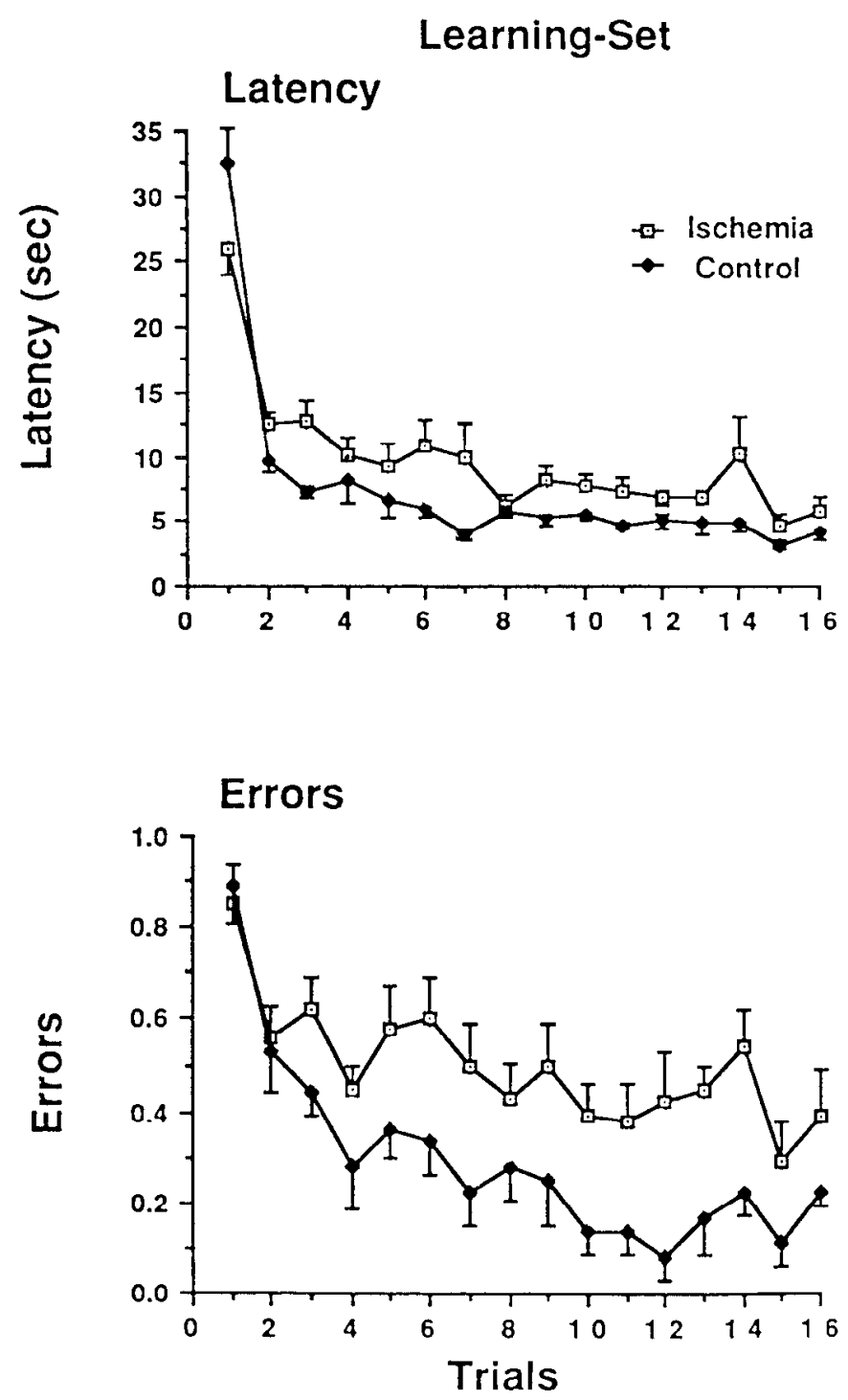

Figure 4. Mean latency and errors on a complex learning-set task that required the animals to locate the hidden escape platform at a new location on each of $6 \mathrm{~d}$. Sixteen trials were given each day, and curves represent the mean group performance. Note that although both groups displayed rapid acquisition, first trial performance of the control group was higher than the ischemia group (they spent longer searching for the platform at its previous day's location) but that their performance on subsequent trials was superior (they learned the new location more quickly). The reduced performance of the ischemia group was significant for both latency $(p=<0.05)$ and errors $(p<0.01)$.

of the long recovery period of 13-15 weeks, this is unlikely for the following reasons. Firstly, acidophilic cell remnants were present and identifiable even after this survival period. Second, when postnecrotic neuronal cytolysis was complete, microglial neuronophagic nodules were observed in the neuropil. Last, examination of subserially sectioned rat brains after identical ischemic durations but only 1 week survival revealed quantitatively and qualitatively similar damage virtually limited to the hippocampus (Jensen and Auer, 1988). At this time, neuronal cytorrhexis and cytolysis has not yet occurred and necrotic neurons are easily identifiable. The fact that the CAl pyramidal cells comprise an essential link in the chain of information flow from the dentate granule cell, to CA3 pyramidal cell, to CA1 


\section{Pattern Discrimination}

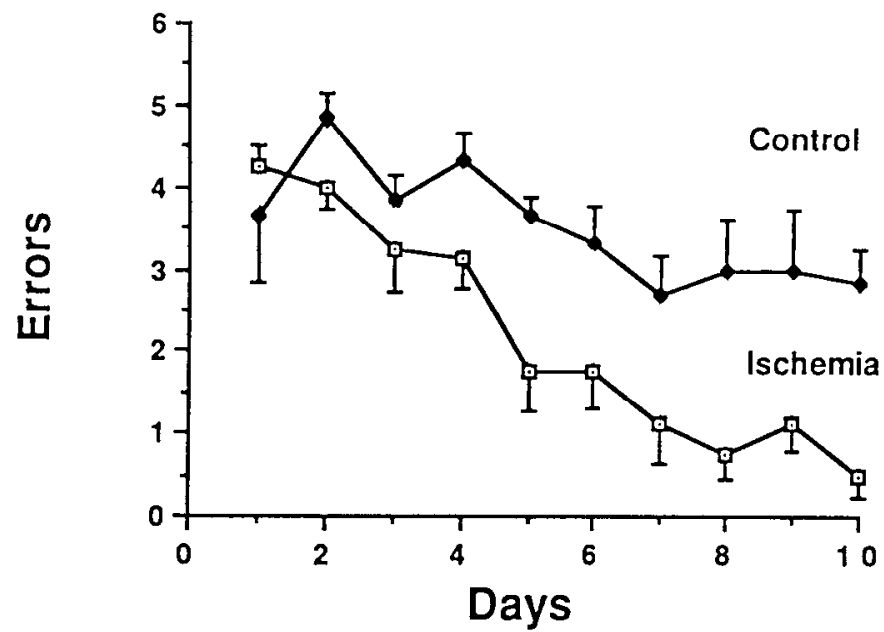

Figure 5. Performance of control and ischemia groups on a patterndiscrimination task. The inferior performance of the control group ( $p$ $<0.01$ ) occurred because they persisted in attempting to use a place response to solve the task.

pyramidal cell, and finally to the subiculum likely accounts for the fact that even restricted lesions of the CAl zone can give rise to memory deficits (Zola-Morgan et al., 1986), although the anatomic basis for hippocampal memory deficits may require consideration of more than the trisynaptic pathway (Braitenberg and Schuz, 1983).

It is not clear from the existing literature how much ischemic hippocampal damage must occur in order to produce a deficit, although near-complete lesions of CA1 certainly suffice (ZolaMorgan et al., 1986). A previous neurobehavioral study using operant conditioning in gerbils found no permanent deficit 8 weeks after right carotid occlusion causing unilateral CA1 pyramidal cell necrosis (Bothe et al., 1986), but another group of workers has shown long-term defects in "working" (trial-dependent) memory, although not "reference" (trial-independent) memory, after 4-vessel cerebral ischemia in an 8-arm radial maze (Volpe et al., 1984; Davis et al., 1987). These behavioral results are comparable with the present findings in which the impairment on the single place task was not significant, but the impairment of the learning-set task was significant. The single place task can be thought of as mainly a reference memory task (the location of the platform does not change), whereas the learning set task involves a working memory component (the location of the platform changes each day). Whereas in the previous studies, extrahippocampal damage was regularly present in regions including the neocortex, thalamus, caudate nucleus, and CA3 region of the hippocampus, raising the possibility that extrahippocampal damage could have contributed (Whishaw et al., 1987) to the impairments, this was not the case in the present study. Damage was absent in the hippocampal CA3 pyramids and dentate granule cells, caudate nucleus, thalamus, and in all but 2 animals was also absent in the cortex. Thus, the present results not only confirm the main behavioral results of previous workers, they unambiguously demonstrate that damage restricted to only $50 \%$ of the CA1 cells of the hippocampus exceeds the threshold for production of a behavioral deficit.

In man, the relationship of memory function to the hippo- campus may be as important as in the rat. First, the dependence of human memory function on the hippocampus should be expected to be as direct as in the rat, in view of the disproportionate enlargement of the vulnerable Sommer's sector or CA1 zone of the hippocampus as the phylogenetic scale is ascended (Stephan and Manolescu, 1980; Stephan, 1983). Second, the complex demands of life in modern societies may place heavy demands upon the type of conditional or contextual retrieval process, here represented by place navigation, mediated by the hippocampus (Hirsch, 1974; Ross et al., 1984). It is noteworthy in this regard that following cerebral ischemia due to cardiac arrest, up to a third of the survivors return home but not to their previous occupations, possibly related to impaired recall and a persistent change in mental abilities (Earnest et al., 1980). To date, the clinical significance of mild selective neuronal necrosis of Sommer's sector commonly seen in human neuropathology as a consequence of cerebral ischemia has been unclear. The present results suggest that even these mild hippocampal lesions might have clinical significance by causing impairments of learning and memory.

\section{References}

Auer, R. N., Y. Olsson, and B. K. Siesjö (1984a) Hypoglycemic brain injury in the rat. Correlation of density of brain damage with the EEG isoelectric time: A quantitative study. Diabetes 33: 1090-1098.

Aucr, R. N., T. Wicloch, Y. Olsson, and B. K. Sicsjö (1984b) The distribution of hypoglycemic brain damage. Acta Neuropathol. (Berl.) 64: 177-191.

Benveniste, H., J. Drejer, A. Schousboe, and N. H. Diemer (1984) Elevation of the extracellular concentrations of glutamate and aspartate in rat hippocampus during transient cerebral ischemia monitored by intracerebral microdialysis. J. Neurochem. 43: 1369-1374.

Bothe, H.-W., H.-J. Bosma, H. Hofer, K.-A. Hossmann, and W. F. Angermeier (1986) Selective vulnerability of hippocampus and disturbances of memory storage after mild unilateral ischemia of gerbil brain. Stroke 17: 1160-1163.

Braitenberg, V., and A. Schuz (1983) Some anatomical comments on the hippocampus. In Neurobiology of the Hippocampus, W. Seifert, ed., pp. 21-36, Academic, New York.

Collingridgc, G. L., S. J. Kchl, and H. McLennan (1983) The antagonism of amino acid-induced excitations of rat hippocampal CA1 neurones in vitro. J. Physiol. (Lond.) 334: 19-31.

Cummings, J. L., U. Tomiyasu, S. Read, and D. F. Benson (1984) Amnesia with hippocampal lesions after cardiopulmonary arrest. Neurology 34: 679-681.

Davis, H. P., J. R. Baranowski, W. A. Pulsinelli, and B. T. Volpe (1987) Retention of reference memory following ischemic hippocampal damage. Physiol. Behav. 39: 783-786.

Drejer, J., H. Benveniste, N. H. Diemer, and A. Schousboe (1985) Cellular origin of ischemia-induced glutamate release from brain tissue in vivo and in vitro. J. Neurochem. 45: 145-151.

Earnest, M., P. R. Yarnell, S. Merrill, and G. L. Knapp (1980) Longterm survival and neurologic status after resuscitation from out-ofhospital cardiac arrest. Ncurology 30: 1298-1302.

Engelsen, B. A., V. M. Fosse, E. Myrseth, and F. Fonnum (1985) Elevated concentrations of glutamate and aspartate in human ventricular cerebrospinal fluid (vCSF) during episodes of increased CSF pressure and clinical signs of impaired brain circulation. Neurosci. Lett. 62: 97-102.

Greenamyre, J. T., J. M. M. Olson, J. B. Penney, Jr., and A. B. Young (1985) Autoradiographic characterization of N-methyl-d-aspartate-, quisqualate- and kainate-sensitive glutamate binding sites. J. Pharmacol. Exp. Ther. 233: 254-263.

Hirsch, R. (1974) The hippocampus and contextual retrieval of information from memory: A theory. Behav. Biol. 12: 421-444.

Horel, J. A. (1978) A critique of the hippocampal memory hypothesis. Brain 101: 403-445.

Jensen, M. L., and R. N. Aucr (1988) The NMDA antagonist ketamine fails to protect against ischaemic neuronal necrosis in the rat. $\mathrm{Br} . \mathrm{J}$. Anaesth. 61: 206-210. 
Johansen, F. F., M. B. Jørgensen, and N. H. Diemer (1983) Resistance of hippocampal CA-1 interneurons to $20 \mathrm{~min}$ of transient cerebral ischemia in the rat. Acta Neuropathol. (Berl.) 61: 135-140.

Johansen, F. F., J. Zimmer, and N. H. Diemer (1987) Early loss of somatostatin neurons in dentate hilus after cerebral ischemia in the rat precedes CA-1 pyramidal cell loss. Acta Neuropathol. (Berl.) 73: $110-114$

Lorente de Nó, R. (1934) Studies on the striation of the cerebral cortex. II. Continuation of the study of the Ammonic system. J. Psychol. Neurol. 46: 113-177.

Mahut, H., S. Zola-Morgan, and M. Moss (1982) Hippocampal resections impair associative learning and recognition memory in the monkey. J. Neurosci. 2: 1214-1229.

Mishkin, M. (1978) Memory in monkeys severely impaired by combined but not by separate removal of amygdala and hippocampus. Nature 273: 297-298.

Monaghan, D. T., D. Yao, H. J. Olverman, J. C. Watkins, and C. W. Cotman (1985) Autoradiography of ${ }^{3} \mathrm{H}-\mathrm{D}$-2-amino-5-phosphonopentanoate binding sites in rat brain. Neurosci. Lett. 52: 253-258.

Morris, R. G. M., P. Garrud, N. Rawlins, and N. O'Keefe (1982) Place navigation impaired in rats with hippocampal lesions. Nature 297: 681-683.

Morris, R. G. M., J. J. Hagan, and J. N. P. Rawlings (1986) Allocentric spatial learning by hippocampectomised rats: A further test of the "spatial mapping" and "working memory" theories of hippocampal function. Q. J. Exp. Psychol. 38B: 365-395.

Muramoto, O., Y. Kuru, M. Sugishita, and Y. Toyokura (1979) Pure memory loss with hippocampal lesions. A pneumoencephalographic study. Arch. Neurol. 36: 54-56.

O'Keefe, J., and L. Nadel (1978) The Hippocampus as a Cognitive Map, Clarendon, Oxford, UK.

Rose, M. (1926) Die sogenannte Riechrinde beim Menschen und beim Affen. J. Psychol. Neurol. 34: 261-401.

Ross, T. R., W. B. Orr, P. C. Holland, and T. W. Berger (1984) Hippocampectomy disrupts acquisition and retention of learned conditional responding. Behav. Neurosci. 98: 211-225.

Rothman, S. M., and J. W. OIney (1986) Glutamate and the pathophysiology of hypoxic/ischemic brain damage. Ann. Neurol. 19: 105111.

Simon, R. P., J. H. Swan, T. Griffiths, and B. S. Meldrum (1984) Blockade of N-methyl-D-aspartate receptors may protect against ischemic damage in the brain. Science 226:850-852.

Smith, M.-L., G. Bendek, N. Dahlgren, I. Rosén, T. Wieloch, and B. K. Siesjö (1984a) Models for studying long-term recovery following forebrain ischemia in the rat. 2. A 2-vessel occlusion model. Acta Neurol. Scand. 69: 385-401.

Smith, M.-L., R. N. Auer, and B. K. Siesjö (1984b) The density and distribution of ischemic brain injury in the rat after 2-10 minutes of forebrain ischemia. Acta Neuropathol. (Berl.) 64: 319-332.
Sommer, W. (1880) Erkrankung des Ammonshorns als aetiologisches Moment der Epilepsie. Arch. Psychiatry 10:631-675.

Stephan, H. (1983) Evolutionary trends in limbic structures. Neurosci. Biobehav. Rev. 7: 367-374.

Stephan, H., and J. Manolescu (1980) Comparative investigations on hippocampus in insectivores and primates. Z. Mikrosk. Anat. Forsch. 94: 1025-1050.

Sutherland, R. J., I. Q. Whishaw, and B. Kolb (1983) A behavioral analysis of spatial localization following electrolytic, kainate- or colchine-induced damage to the hippocampal formation in the rat. Behav. Brain. Res. 7: 133-152.

Victor, M., J. B. Angevine, E. L. Mancall, and C. M. Fisher (1961) Memory loss with lesions of hippocampal formation. Report of a case with some remarks on the anatomical basis of memory. Arch. Neurol. 5: $26-45$.

Volpe, B. T., and W. Hirst (1983) The characterization of an amnesic syndrome following hypoxic ischemic injury. Arch. Neurol. 40:436440.

Volpe, B. T., W. A. Pulsinelli, J. Tribuna, and H. P. Davis (1984) Behavioral performance of rats following transient forebrain ischemia. Stroke 15: 558-562.

Whishaw, I. Q. (1985a) Formation of a place learning-set in the rat: A new procedure for neurobehavioral studies. Physiol. Behav. 35: 845-851.

Whishaw, I. Q. (1985b) Cholinergic receptor blockade in the rat impairs locale but not taxon strategies for place navigation in a swimming pool. Behav. Neurosci. 99: 979-1005.

Whishaw, I. Q. (1987) Hippocampal granule cell and CA3-4 lesions impair formation of a place learning-set in the rat and induce reflex epilepsy. Behav. Brain. Res. 24: 59-72.

Whishaw, I. Q., and B. F. Petrie (1989) Cholinergic receptor blockade in the rat impairs strategy selection but not learning and memory in nonspatial visual discrimination tasks. Behav. Neurosci. 102: 662677.

Whishaw, I. Q., G. Mittleman, S. T. Bunch, and S. B. Dunnett (1987) Impairments in the acquisition, retention and selection of spatial navigation strategies after medial caudate-putamen lesions in rats. Behav. Brain Res. 24: 125-138.

Wigström, H., B. Gustafsson, and Y.-Y. Huang (1986) Mode of action of excitatory amino acid receptor antagonists on hippocampal longlasting potentiation. Neuroscience 17: 1105-1115.

Zola-Morgan, S., and L. R. Squire (1986) Memory impairment in monkeys following lesions limited to the hippocampus. Behav. Neurosci. 100: 155-160.

Zola-Morgan, S., L. R. Squire, and D. G. Amaral (1986) Human amnesia and the medial temporal region: Enduring memory impairment following a bilateral lesion limited to field CAI of the hippocampus. J. Neurosci. 6: 2950-2967. 